\title{
Hepatosellüler Karsinomda Klinik ve Prognostik Özelliklerin Değerlendirilmesi: Tek Merkez Deneyimi
}

\section{Evaluation of Clinical and Prognostic Features in Hepatocellular Carcinoma: A Single Center Experience}

\author{
Atike Pınar Erdoğan ${ }^{1 *}$, Ferhat Ekinci ${ }^{1}$, Ahmet Özveren ${ }^{2}$, Cumali Çelik ${ }^{1}$, Gonca Akdere Ateş ${ }^{1}$, Seval Akay ${ }^{1}$, Ahmet \\ Dirican $^{1}$ \\ ${ }^{1}$ Manisa Celal Bayar Üniversitesi Tıp Fakültesi Tıbbi Onkoloji Bilim Dalı, Manisa, Turkey
e-mail: atike.erdogan@cbu.edu.tr, drferhatekinci@hotmail.com, cumalicelik84@ hotmail.com,
gonca_akdere@hotmail.com,drsevalsekerler@hotmail.com, ahmetdirican@yahoo.com, \\ ahmet_ozveren@yahoo.com \\ ORCID: 0000-0003-4859-7574 \\ ORCID: 0000-0002-9317-942X \\ ORCID: 0000-0001-9236-1716 \\ ORCID: 0000-0003-0373-7561 \\ ORCID: 0000-0002-1235-6739 \\ ORCID: 0000-0001-6992-9289 \\ ORCID: 0000-0002-6432-5432 \\ *Sorumlu yazar/ Corresponding Author: Atike Pınar Erdoğan
}

Gönderim Tarihi / Received: 25.10.2020

Kabul Tarihi / Accepted: 16.02.2021

DOI: $10.34087 /$ cbusbed.830940

\section{$\ddot{\mathbf{O} z}$}

Giriş ve Amaç: Hepatoselüler karsinom (HCC), kanserin yaygın bir nedenidir ve çoğu HCC hastasında altta yatan siroz vardır. Retrospektif olarak kliniğimizde takipli HCC'li hastalarını karakterize etmeyi, sağkalımı araştırmayı ve sağkalım için öngörücü faktörleri belirlemeyi amaçladık.

Gereç ve Yöntemler: Manisa Celal Bayar Üniversitesi Tıbbi Onkoloji Polikliniğginde 2014-2019 yılları arasında HCC teşhisi konan tüm hastalar geriye dönük olarak çalışmaya kaydedildi. Genel sağkalım Kaplan -Meier yöntemi kullanılarak hesaplandı. Sağkalım için öngördürücü faktörleri belirlemek için çok değişkenli Cox regresyon analizi yapild1.

Bulgular: Kliniğimizde takipli 40 HCC hastasının medyan tanı yaşı 66 olup \%90’ı erkektir. Hepatit B virüs (HBV) enfeksiyonu en sık etyolojik sebeptir. C-Reaktif Protein (CRP) seviyesi daha yüksek olan hastaların sağkalım sürelerinin daha kısa olduğu görülmüştür. AFP düzeyi ile sağkalım arasında anlamlı korelasyon izlenmemiştir. Sonuç: Bölgemizde HBV'ye bağlı HCC'nin daha sık görüldüğü saptanmıştır. Hedefe yönelik tedavilerin umut vadettiği ve bu yönde prediktif belirteçlere ihtiyaç duyulduğu düşünülmektedir.

Anahtar kelimeler: Etyoloji, Hepatosellüler kanser, Prognoz, Tedavi.

\section{Abstract}

Objective: Hepatocellular carcinoma (HCC) is a common cause of cancer, and most of HCC patients have underlying cirrhosis. We aimed to retrospectively characterize patients with HCC who are followed up in our clinic, to investigate survival and to determine predictive factors for survival.

Materials and Methods: All patients diagnosed with HCC in Manisa Celal Bayar University Medical Oncology Outpatient Clinic between 2014-2019 were enrolled in the study retrospectively. Overall survival was calculated using the Kaplan-Meier method. Multivariate Cox regression analysis was performed to determine predictive factors for survival.

Results Median age at diagnosis of 40 HCC patients followed up in our clinic is 66 and $90 \%$ of them are male. Hepatitis B virus (HBV) infection is the most common etiological cause. It was observed that patients with higher 
C-Reactive Protein (CRP) levels had shorter survival times. There was no significant correlation between AFP level and survival.

Conclusion: It has been determined that HCC due to HBV is more common in our region. It is thought that targeted therapies are promising and predictive markers are needed in this direction.

Keywords: Etiology, Hepatocellular carcinoma, Prognosis, Treatment.

\section{Giriş}

Hepatoselüler karsinom (HCC) karaciğer kanserlerinin en sık görülen alt türüdür ve tüm karaciğer kanserlerinin \% 75'ini oluşturur. HCC tüm kanserlere bağlı ölüm nedenleri arasında dördüncü sıradadır. [1] Bu agresif kanser genellikle ileri evrede teşhis edilir ve karaciğer fonksiyonları bozulmuş olan hastalarda prognoz kötüdür.

HCC için ana risk faktörleri, hepatit B virüsü (HBV) ve hepatit $\mathrm{C}$ virüsü (HCV) ile kronik enfeksiyon, aflatoksinle kontamine gida maddeleri, yoğun alkol alımı, alkole bağlı olmayan yağlı karaciğer hastalığı (NAYKH), obezite, sigara ve tip 2 diyabetes mellitus (DM)'dir. [2] HCC'li hastaların \% 90'ında, genellikle kronik alkol tüketimi veya kronik viral hepatit B ve C'ye bağlı olarak siroz vardır. HCC, bazı kronik hepatit B enfeksiyonu vakalarında siroz yokluğunda da ortaya çıkabilir. [3]

Başlıca risk faktörleri bölgeden bölgeye değişmekle birlikte kronik viral hepatitler genellikle en sik sebeptir. Çoğu yüksek riskli HCC bölgesinde (Çin, Doğu Afrika), anahtar belirleyiciler kronik HBV enfeksiyonu ve aflatoksin maruziyetidir, diğer ülkelerde (Japonya, Mısır), HCV enfeksiyonu baskın nedendir. Karaciğer kanseri vakalarının önlenmesi, 1982'den beri HBV'ye karşı geliştirilen aşı yoluyla mümkün olmuştur ve bu aşının gelecekteki faydaları, aşılanan nesiller karaciğer kanserinin yaygın hale geldiği yaşlara ulaştıkça artacaktır. [4]

HCC'de sağkalımı tahmin etmek genellikle zordur; çünkü karaciğer fonksiyonlarının da dikkate alınması gerektiğinden TNM evreleme sistemi doğrudan prognozu öngördüremez. Yıllar içinde, prognostik faktörleri belirlemeye yönelik birçok çalışma yapılmıştır. [5] En sık kullanılan prognostik model aynı zamanda bir klinik evreleme ve tedavi sistemi olan Barselona Klinik Karaciğer Kanseri (BCLC) evreleme sistemidir. BCLC modeli, tümör boyutu, karaciğer fonksiyonu ve fiziksel durum kombinasyonuna dayalı bir puanlama ile hastaları erken, orta, ileri ve terminal şeklinde gruplandırıp her aşama için farklı tedavi seçenekleri sunar. [6]

Görüntüleme yöntemleri ve tedavide son on y1lda kaydedilen ilerlemeyle artık erken ve orta evrede HCC teşhisi konan hastalarda sağkalımı iyileştirebilecek hedefe yönelik tedaviler mevcuttur.

$\mathrm{Bu}$ çalışmada, bir Ege Bölgesi hastanesi olan kliniğimizde takip edilmiş HCC'li hastalarının karakterize edilmesi ve sağkalım için öngörücü faktörlerin belirlenmesi hedeflenmiştir.

\section{Materyal ve Metot}

\subsection{Yöntem}

HCC tanısı çoğu olguda hepatik lezyonun üç fazlı bilgisayarlı tomografi (BT) taramasında arteriyel fazda hipervaskülaritesinin ve venöz / portal venöz fazda "arınma/washout" gözlenmesi şeklindeki tipik radyolojik vasküler paterni ile konulmuştur. Diğer olgular ise manyetik rezonans görüntüleme (MRG), pozitron emisyonu tomografi (PET) veya histopatolojik olarak tanı almıştır.

Manisa Celal Bayar Üniversitesi T1bbi Onkoloji Polikliniğinde 2014-2019 tarihleri arasında HCC tanısı ile takip edilen 40 hastaya ait dosyalar retrospektif olarak incelenmiştir. Demografik ve klinik değişkenler; tanı anındaki yaş, cinsiyet, yaşam ortamı (kırsal veya kentsel), karaciğer sirozu, viral hepatit, sigara, alkol alımı, NAYKH ve diğer siroz faktörleri, Child-Pugh skoru, HBV tedavisi, HCV tedavisi, tip 2 DM, statin ve aspirin tedavisi, kan grubu, uzunluk ve ağırlık, sorafenib tedavisi, BCLC ve TNM evreleme, lokal ablatif tedavi, cerrahi tedavi olarak kaydedilmiştir.

\subsection{Istatistiksel Analiz}

Tüm istatistiksel analizler Celal Bayar Üniversitesi'ne lisanslı SPSS for Windows sürüm 22 (SPSS Inc., Chicago, IL, ABD) ile yapıldı. Tüm istatistiksel değerlendirmeler iki yönlüdür ve 0.05 'lik bir p değeri istatistiksel olarak anlamlı kabul edilmiştir. Genel sağkalım (OS), hastanın tanısından itibaren herhangi bir nedenden ötürü ölüm tarihine veya son takip tarihine kadar hesaplanmıştır. Kümülatif sağkalımdaki farklılıklar Kaplan - Meier yöntemi ve bir log-rank testi kullanılarak belirlenmiştir. Sağkalım farkı için tek değişkenli ve çok değişkenli analizler Cox orantılı risk modeli kullanılarak gerçekleştirilmiştir. Cut-off değerleri için ROC eğrisi analiz edilmiştir.

Çalışma protokolü Manisa Celal Bayar Üniversitesi Etik Kurulu tarafından onaylanmıştır (Sayı: 164.120).

\section{Bulgular ve Tartışma}

Çalışmaya dahil edilen 40 hastanın genel özellikleri tablo 1 'de gösterilmiştir. Tüm hasta grubunun medyan genel sağkalım süresi (mOS) 18.9 ay olarak bulundu. En yaygın ilk üç etyolojik faktör sırasıyla HBV enfeksiyonu, HCV enfeksiyonu ve Tip 2 diyabetti.

Son on yılda, HCC moleküler mekanizmalarıyla ilgili daha fazla bilgi sahibi olunması, tirozin kinaz inhibitörleri ve immünoterapi dahil etkili sistemik tedavilerin geliştirilmesine yol açmıştır. Sorafenib oral yolla kullanılan, Raf kinaz ve vasküler endotelyal büyüme faktörü reseptörü (VEGFR) hücre içi yolağını inhibe eden küçük moleküllü bir tirozin kinaz inhibitörüdür. Faz 3 plasebo kontrollü SHARP çalışması ile en iyi destek bakıma kıyasla sağkalım faydası sağladığ1 gösterilmiştir. 602 hastanın randomize edildiği çalışmada Sorafenib alan grupta mOS 10.7 ay iken plasebo grubunda 7.9 ay bulunmuştur. (p:0.001) Medyan progresyonsuz sağkalım (mPS) ise 5.5 aydır.[7 ] 
Tablo 1. Hasta Özellikleri

\begin{tabular}{|c|c|}
\hline Hasta Özellikleri & n(\%) \\
\hline \multicolumn{2}{|l|}{ Cinsiyet } \\
\hline Kadın & $4(10)$ \\
\hline Erkek & $36(90)$ \\
\hline Tanı yaşı, mean (SD) & $66(9.3)$ \\
\hline \multicolumn{2}{|l|}{ Yaşam Ortamı } \\
\hline Kırsal & $5(12.5)$ \\
\hline Kentsel & $24(60)$ \\
\hline Bilinmeyen & $11(27.5)$ \\
\hline \multicolumn{2}{|c|}{ Child-Pugh Sınıflaması } \\
\hline A & $38(95)$ \\
\hline $\mathrm{B}$ & $0(0)$ \\
\hline $\mathrm{C}$ & $2(5)$ \\
\hline \multicolumn{2}{|l|}{ TNM evresi } \\
\hline Evre I-II & $18(45)$ \\
\hline Evre III-IV & $22(55)$ \\
\hline \multicolumn{2}{|l|}{ Sigara } \\
\hline Hiç içmemiş & $7(17.5)$ \\
\hline Bırakmış & $2(5)$ \\
\hline İçiyor & $14(35)$ \\
\hline Bilinmeyen & $17(42.5)$ \\
\hline \multicolumn{2}{|l|}{ Alkol } \\
\hline Yok & $21(52.5)$ \\
\hline Düzenli & $2(5)$ \\
\hline Bilinmeyen & $17(42.5)$ \\
\hline \multicolumn{2}{|l|}{ Siroz varlığı } \\
\hline Var & $8(20)$ \\
\hline Yok & $32(80)$ \\
\hline \multicolumn{2}{|l|}{ Diabetes Mellitus } \\
\hline Var & $5(12.5)$ \\
\hline Yok & 35 (87.5) \\
\hline \multicolumn{2}{|l|}{ Metabolik Sendrom } \\
\hline Var & $0(0)$ \\
\hline Yok & $40(100)$ \\
\hline \multicolumn{2}{|c|}{$\begin{array}{l}\text { Karaciğer Hastalığının } \\
\text { Etyolojisi }\end{array}$} \\
\hline $\mathrm{HBV}$ & $28(70)$ \\
\hline $\mathrm{HCV}$ & $7(17.5)$ \\
\hline Tip 2 DM & $5(12.5)$ \\
\hline Alkol & $2(5)$ \\
\hline \multicolumn{2}{|l|}{ Tedavi } \\
\hline Transplant & $1(2.5)$ \\
\hline Rezeksiyon & $3(7.5)$ \\
\hline Lokal ablatif & $15(37.5)$ \\
\hline Sorafenib & $15(37.5)$ \\
\hline Regorafenib & $2(5)$ \\
\hline \multicolumn{2}{|l|}{ AFP $(\mathrm{ng} / \mathrm{ml})$} \\
\hline$<20$ & $21(52.5)$ \\
\hline $20-399$ & $10(25)$ \\
\hline$>400$ & $9(22.5)$ \\
\hline
\end{tabular}

$\mathrm{HBV}=$ Hepatit $\mathrm{B}$ virus; $\mathrm{HCV}=$ Hepatit $\mathrm{C}$ virus; $\mathrm{NAYKH=Non}$ Alkolik Yağlı Karaciğer Hastalı̆ $\breve{1}$ AFP=Alfa fetoprotein; NLO=Nötrofil Lenfosit Oranı
Bizim hasta grubumuzda Sorafenib 15 hastada kullanılmış, hastalık progresyonu, ciddi toksisite veya hasta onamını geri çekmesine kadar devam edilmiştir. Sorafenib tedavisine $6(\% 15)$ hastada progresyon, 8 (\%20) hastada stabil yanıt, 1 (\%2.5) hastada k1smi yanıt gözlenmiştir. Sorafenib ile mPS 9.9 ay bulunmuştur.

Sorafenib ile yapılan çalışmalarda HCV pozitif sirotik hastaların tedaviden daha fazla yarar gördüğü bildirilmiş olup prediktif biyobelirteçlerin tanımlanması gerektiğine vurgu yapılmıştır. Buradan hareketle karaciğer enzimleri, AFP düzeyi gibi plazma biyobelirteçleri ile ilgili de çalışmalar yapılmakta; ancak henüz klinik pratikte kabul gören bir değer bulunmamaktadır. [8] Bizim çalıșmamızda da AFP değeri ile sorafenibe yanıt süresi birlikte değerlendirilmiş ve herhangi bir korelasyon izlenmemiştir.

Regorafenib VEGFR 1-2-3 dahil olmak üzere anjiojenik, stromal ve onkojenik reseptör tirozin kinazları inhibe eden oral yolla kullanılan bir moleküldür. Sorafenib ile progrese olan HCC hastalarında kullanımının değerlendirildiği RESORCE çalışmasında Child-Pugh skoru A olan 573 hasta randomize edilmiş, regorafenib alan kolda mOS 'nin 10.6 ay olduğu ve plaseboya göre (7.8 ay, HR:0.63) anlamlı derecede uzadığı izlenmiştir. [9] Hasta sayısının az olması nedeniyle çalışmamızda regorafenib ile sağkalım analizi yapılamamış ancak regorafenib kullanan 2 hastanın da literatürle uyumlu sağkalım süresine sahip olduğu gözlenmiştir.

Lökositlerin strese verdiği yanıt, nötrofil sayısında artışa ve lenfosit sayısında azalmaya neden olduğundan klinik pratikte bu iki alt grubun birbirine oranı inflamasyonun bir göstergesi olarak kullanılmaktadır. Yüksek nötrofil lenfosit oranının (NLO) artmış tümör inflamasyonu ve azalmış antitümör immün yanıtı gösterebileceği ve kötü prognoz belirteci olduğuna dair çalışmalar mevcuttur. $[10,11]$ Bizim hasta grubumuzda ROC analizine göre NLO cutoff değeri 2,94 olarak belirlenmiş, NLO < 2.94 olanların mOS 12.2 ay, >2.94 olanların mOS 11 ay olarak bulunmuş, rakamsal olarak 1.2 ay daha kısa sağkalımla ilişkili bu değer istatistiksel olarak anlamlı bir farka ulaşmamıştır. Yine inflamatuar bir belirteç olan CReaktif Protein (CRP)'nin solid tümörlerde prognostik bir belirteç olabileceğine yönelik kanıtlar mevcuttur. Bizim hasta grubumuzun değerlerine bakıldığında da CRP yüksek olan hastaların sağkalımı istatistiksel olarak anlamlı şekilde daha kısa saptanmıştır. (p:0.029)[12] AFP, HCC takibinde en sık kullanılan belirteçtir. HCC'li hastaların \% 60-70'inde serum AFP konsantrasyonu artar. $\mathrm{Bu}$ glikoprotein fetal karaciğer ve yolk sac tarafından ilk trimesterde salgılanır ve doğumdan sonra hızla azalır. Serum AFP düzeyi akut ve kronik hepatit gibi benign durumlarda yükselebileceği gibi, intrahepatik kolanjiokarsinom veya embriyonel tümörler gibi HCC dışı malign hastalıklarda da yükselebilir. $\mathrm{Bu}$ glikoprotein, HCC riski taşıyan sirozlu hastaların sürveyansı için klinik uygulamada uzun yıllar ölçülmüştür, ancak bu kullanım, zayıf teşhis performansı nedeniyle eleştirilmiştir. Trevisani ve ark. çalışmasında $\% 5 \mathrm{HCC}$ prevalansına sahip bir popülasyonda $20 \mathrm{ng} /$ mL'lik bir cutoff değeri için, \% 97.7'lik bir negatif 
prediktif değer ve \% 25'lik bir pozitif prediktif değer bulunmuştur. [13] Bu nedenle AFP, HCC'nin dışlanması için yararlı, ancak erken tespiti için zayıf olarak değerlendirilmiştir. Son zamanlarda dikkatler, HCC tedavisi sırasında AFP'deki değişikliklerin ölçülmesine yönelmiştir. Shao ve ark., sorafenib dahil olmak üzere çeşitli antianjiyojenik ajanlarla kombinasyon halinde metronomik kemoterapinin etkinliğini araştıran klinik araştırmalara kayıtlı 72 hastanın verilerini analiz etmiş ve tedavinin 2-4 haftasında AFP'de >\% 20 azalmanın tedaviye yanıtı ve prognozu öngördüğünü bildirmişlerdir. [14] Bizim çalışmamızda AFP değeri ile mOS arasında bir korelasyon gözlenmemiştir, bu durum hasta sayısının az olmasıyla ilişkili olabilir.

\section{Conclusion}

Çalışmamızda merkezimizde 2014-2019 yılları arasında takip edilen HCC hastaları incelenmiş, yarısından fazlasında HBV enfeksiyonu olduğu görülmüştür. HBV enfeksiyonunun önlenmesine yönelik primer koruma çalışmaları arttıkça HCC görülme sıklığı da azalacaktır. Sorafenib ve regorafenib gibi hedefe yönelik tedavilerin kullanıma girmesi hastalığın agresif seyrini yavaşlatmıştır. Bölgesel risk faktörlerinin belirlenmesi ve moleküler tedavilere yanıt veren grupların tanımlanması için geniş hasta grupları ile yapılmış çalışmalara ihtiyaç vardır.

\section{Teşekkür ve Bilgilendirme}

Çalışmanın yürütülmesi ve arşiv verilerine ulaşılmasında destek veren Prof. Dr. Gamze Göksel'e minnettariz.

\section{References}

1.Bray, F, Ferlay, J, ve ark. Global cancer statistics 2018 : GLOBOCAN estimates of incidence and mortality worldwide for 36 cancers in 185 countries, A Cancer Journal for Clinicians, 2018, 68(6), 394-424.

2.London, W.T, Petrick, J.L, McGlynn, K.A, Liver cancer, In: Thun M.J, Linet, M.S, Cerhan, J.R, Haiman, C.A, Schottenfeld D, eds. Cancer Epidemiology and Prevention. 4th ed. New York: Oxford University Press; 2018, 635-660.

3.Tang, A, Hallouch, O, Chernyak, V, Kamaya, A, Sirlin, C.B, Epidemiology of hepatocellular carcinoma: target population for surveillance and diagnosis. Abdominal Radiology (NY). 2018, 43(1), $13-25$

4. World Health Organization. Global Health Observatory (GHO) data: Hepatitis B 3rd Dose (HepB3) Immunization Coverage. Geneva: World Health Organization; 2017. who.int/gho/immunization/hepatitis/en/.

5. Vogeler, M, Mohr, I, Pfeiffenberger, J, Sprengel, S.D, Klauss, M,ve ark, Applicability of scoring systems predicting outcome of transarterial chemoembolization for hepatocellular carcinoma. Journal of Cancer Research and Clinical Oncology. 2020,146(4), 1033-1050.

6. Ayuso, C, Rimola, J, Vilana, R, Burrel, M,ve ark, Diagnosis and staging of hepatocellular carcinoma (HCC): current guidelines. European Journal of Radiology 2018, 101,72-81.

7. Llovet, J.M, Ricci, S, Mazzaferro, V, ve ark, Sorafenib in advanced hepatocellular carcinoma. New England Journal of Medicine 2008 , 359,378 .

8. Personeni, N, Rimassa, L, Pressiani, T, ve ark, Molecular determinants of outcome in sorafenib-treated patients with hepatocellular carcinoma, Journal of Cancer Research and Clinical Oncology 2013, 139, 1179.

9. Bruix, J, Qin, S, Merle, P, ve ark, Regorafenib for patients with hepatocellular carcinoma who progressed on sorafenib treatment
(RESORCE): a randomised, double-blind, placebo-controlled, phase 3 trial, Lancet 2017, 389, 56.

10. Stotz, M, Gerger, A, Eisner, F, ve ark, Increased neutrophillymphocyte ratio is a poor prognostic factor in patients with primary operable and inoperable pancreatic cancer. British Journal of Cancer, 2013,109, 416-421.

11. Azab, B, Mohammad, F, Shah, N, ve ark, The value of the pretreatment neutrophil lymphocyte ratio vs. platelet lymphocyte ratio in predicting the long-term survival in colorectal cancer, Cancer Biomarkers, 2014, 14, 303-312.

12. Shrotriya, S, Walsh, D, Nowacki, A.S, ve ark, Serum C-reactive protein is an important and powerful prognostic biomarker in most adult solid tumors, PLoS One, 2018, 13(8), e0202555.

13. Trevisani, F, DIntino, P.E, Morselli-Labate, A.M, ve ark, Serum afetoprotein for diagnosis of hepatocellular carcinoma in patients with chronic liver disease: Influence of $\mathrm{HBsAg}$ and anti-HCV status, Journal of Hepatology, 2001, 570-575.

14.Shao, Y.Y, Lin, Z.Z, Hsu, C, Shen, Y.C, Hsu, C.H, Cheng, A.L, ve ark., Early alpha-fetoprotein response predicts treatment efficacy of antiangiogenic systemic therapy in patients with advanced hepatocellular carcinoma, Cancer, 2010, 116, 4590-4596.

http://edergi.cbu.edu.tr/ojs/index.php/cbusbed isimli yazarın CBU-SBED başlıklı eseri bu Creative Commons Alıntı-Gayriticari4.0 Uluslararası Lisansı ile lisanslanmıştır.

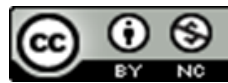

